Marquette University

e-Publications@Marquette

College of Nursing Faculty Research and

Publications

Nursing, College of

$12-1-2011$

\title{
Prehabilitation Before Total Knee Arthroplasty Increases Strength and Function in Older Adults With Severe Osteoarthritis
}

Ann M. Swank

University of Louisville

Joseph B. Kachelman

University of Louisville

Wendy Bibeau

University of Maryland

Peter M. Quesada

University of Louisville

John Nyland

University of Louisville

See next page for additional authors

Accepted version. Journal of Strength and Conditioning Research, Vol. 25, No. 2, (December 2011):

318-325. DOI. C 2011 Lippincott Williams \& Wilkins, Inc. Used with permission. 
Authors

Ann M. Swank, Joseph B. Kachelman, Wendy Bibeau, Peter M. Quesada, John Nyland, Arthur Malkani, and Robert V. Topp 


\section{Prehabilitation Before Total Knee Arthroplasty Increases Strength and Function in Older Adults with Severe Osteoarthritis}

By: Ann M. Swank, Joseph B. Kachelman, Wendy Bibeau, Peter M. Quesada, John Nyland, Arthur Malkani, and Robert V. Topp

\section{Abstract}

Preparing for the stress of total knee arthroplasty (TKA) surgery by exercise training (prehabilitation) may improve strength and function before surgery and, if effective, has the potential to contribute to postoperative recovery, Subjects with severe osteoarthritis (OA), pain intractable to medicine and scheduled for TKA were randomized into a usual care (UC) group $(n=36)$ or usual care and exercise $(U C+E X)$ group $(n=35)$, The UC group maintained normal daily activities before their TKA. The UC + EX group performed a comprehensive prehabilitation program that included resistance training using bands, flexibility, and step training at least 3 times per week for 4-8 weeks before their TKA in addition to UC, Leg strength (isokinetic peak torque for knee extension and flexion) and ability to perform functional tasks (6-minute walk, 30 second sit-to- stand repetitions, and the time to ascend and descend 2 flights of stairs) were assessed before randomization at baseline (T1) and 1 week before the subject's TKA (T2), Repeated-measures analysis of variance indicated a significant group by time interaction $\left(p^{\prime} 0,05\right)$ for the 30 -second sit to stand repetitions, time to ascend the first flight of stairs, and peak torque for knee extension in the surgical knee, Pre habilitation increased leg strength and the ability to perform functional tasks for UC + EX when compared to UC before TKA. Short term (4-8 weeks) of prehabilitation was effective for increasing strength and function for individuals with severe $O A$. The program studied is easily transferred to a home environment, and clinicians working with this population should consider prehabilitation before TKA.

Key Words: arthritis, exercise, rehabilitation, aging

\section{Introduction}

Osteoarthritis $(\mathrm{OA})$ is the most common form of arthritis and is the leading cause of disability in the United States (11). Approximately 21 million Americans over the age of 45 years suffer from some form of $\mathrm{OA}(4,5,12)$ with the weight-bearing joints of the lower

Swank et al., 1 
extremities most commonly affected (3). Osteoarthritis of the knee is associated with progressive declines in strength, flexibility, and reduced ability to perform functional tasks $(6,20)$. This condition is initially treated pharmacologically but frequently progresses to where total knee joint arthroplasty (TKA) is the only effective treatment for long-term relief of the pain (15).

Although TKA surgery is effective for relief of pain, reduced leg strength may be present for years after surgery $(16,30)$. Weak lower extremity muscles predispose older adults to falls and result in declines in the ability to perform functional tasks (20). Individuals with knee OA have significantly lower quadriceps strength compared to their nonaffected leg or with healthy age-matched controls $(21,24)$. Various exercise programs designed to improve leg strength and ability to perform functional tasks of individuals before TKA have demonstrated limited success $(2,8,27)$. These investigations assessed functional ability primarily through the measurement of perception and self-report of function $(2,8,27)$. Assessment of functional ability using tests shown to be predictive of function including 6minute walk; 30 -second sit to stand and time to ascend and descend 2 flights of stairs may be more sensitive to an exercise intervention (7).

This study evaluated the impact of a short-term prehabilitation program of 4-8 weeks performed before TKA surgery on leg strength and performance of functional tasks among subjects with severe knee $O A$ and joint pain that was intractable to medicine randomly assigned to usual care (UC) or usual care and exercise (UC + EX). The authors hypothesized that subjects engaged in a resistance band, flexibility and step exercise program before their TKA will demonstrated improved leg strength and ability to perform functional tasks when compared to subjects not engaging in this program.

\section{Methods}

\section{Experimental Approach to the Problem}

This randomized controlled study compared leg strength and performance of functional tasks among subjects with knee $O A$ and pain not responsive to medicine and scheduled for TKA. Subjects were randomly assigned to UC or UC + EX before their TKA. Subjects were scheduled for 2 preoperative data collection points. Initial testing (T1) was performed 4-weeks before surgery after which subjects were randomized to 1 of the 2 study groups. The 4- to 8-week time frame was dictated by the scheduling of their TKA as 
determined by the surgeon's schedule. Final testing (T2) occurred during the week before the subject's TKA. The order of testing was the same for both T1 and T2 and consisted of a 6-minute walk test, 30-second sit-to-stand, stair ascent, stair descent, and concluded with assessments of knee flexion and extension strength. The exercise program consisted of exercises specific for increasing leg strength and function.

\section{Subjects}

Subjects enrolled in this study had severe OA with pain not responsive to medication and scheduled for TKA. Subject's inactivity primarily related to join pain and were recruited through a single orthopedic surgeon's office. After a surgical date was set for the individual's TKA procedure, research personnel discussed with the potential subject the general purpose and methods of the study. Potential subjects were excluded during this interview if they reported a history of uncontrolled angina, cardiomyopathy severe enough to compromise cardiac functioning, any other health problem that would prohibit moderate exercise, or if they were taking nitrates, digitals, or phenothiazines (1). Once all questions and concerns were addressed, the subject completed an informed consent that was approved by the University's Human Studies Committees. Ninety subjects were screened and 19 were eliminated based on inclusion and exclusion criteria. Three subjects were excluded based on cardiopulmonary comorbidities that precluded modest exercise, and 16 were excluded because of excessive pain with modest exercise. A total of 71 subjects (36 controls, 35 exercises) were recruited and completed both testing sessions. All data collection and exercise education and training took place in the University of Louisville's Exercise Physiology Laboratory within the College of Education and Human Development.

\section{Procedures}

Subjects were scheduled for 2 preoperative testing sessions. Initial testing (T1) was performed 4-8 weeks (average length was 5.5 weeks) before surgery after which subjects were randomized to 1 of the study groups. Final testing (T2) occurred during the week before the subject's TKA. The order of testing was the same for both T1 and T2 and consisted of a 6-minute walk test, 30-second sit-to-stand, stair ascent, stair descent, and concluded with assessments of knee flexion and extension strength. Each assessment was separated by a 3-minute rest interval. In addition a visual analog scale (VAS: 1-10) was

Swank et al., 3 
Table 1. Recommended exercise progression for 8-week prehabilitation program.

\begin{tabular}{|c|c|c|c|c|}
\hline Exercise & Weeks 1-2 & Weeks 3-4 & Weeks 5-6 & Week 7-8 \\
\hline Warm-up & 5-min walking & 5-min walking & 5-min walking & 5-min walking \\
\hline Squat & $\begin{array}{c}1 \text { Set } \times 10 \text { reps @ } \\
\text { low resistance }\end{array}$ & $\begin{array}{l}2 \text { Sets } \times 10 \text { reps } @ \\
\text { low resistance }\end{array}$ & $\begin{array}{l}1 \text { Set } \times 10 \text { reps @ } \\
\text { moderate resistance }\end{array}$ & $\begin{array}{l}2 \text { Sets } \times 10 \text { reps @ } \\
\text { moderate resistance }\end{array}$ \\
\hline Leg extension & $\begin{array}{l}1 \text { Set } \times 10 \text { reps @ } \\
\text { low resistance }\end{array}$ & $\begin{array}{l}2 \text { Sets } \times 10 \text { reps @ } \\
\text { low resistance }\end{array}$ & $\begin{array}{l}1 \text { Set } \times 10 \text { reps @ } \\
\text { moderate resistance }\end{array}$ & $\begin{array}{l}2 \text { Sets } \times 10 \text { reps @ } \\
\text { moderate resistance }\end{array}$ \\
\hline Leg curl & $\begin{array}{l}1 \text { Set } \times 10 \text { reps } @ \\
\text { low resistance }\end{array}$ & $\begin{array}{l}2 \text { Sets } \times 10 \text { reps } @ \\
\text { low resistance }\end{array}$ & $\begin{array}{l}1 \text { Set } \times 10 \text { reps } @ \\
\text { moderate resistance }\end{array}$ & $\begin{array}{l}2 \text { Sets } \times 10 \text { reps @ } \\
\text { moderate resistance }\end{array}$ \\
\hline Hip abduction & $\begin{array}{c}1 \text { Set } \times 10 \text { reps } @ \\
\text { low resistance }\end{array}$ & $\begin{array}{l}2 \text { Sets } \times 10 \text { reps } @ \\
\text { low resistance }\end{array}$ & $\begin{array}{l}1 \text { Set } \times 10 \text { reps @ } \\
\text { moderate resistance }\end{array}$ & $\begin{array}{l}2 \text { Sets } \times 10 \text { reps @ } \\
\text { moderate resistance }\end{array}$ \\
\hline Hip adduction & $\begin{array}{l}1 \text { Set } \times 10 \text { reps } @ \\
\text { low resistance }\end{array}$ & $\begin{array}{l}2 \text { Sets } \times 10 \text { reps@ } \\
\text { low resistance }\end{array}$ & $\begin{array}{l}1 \text { Set } \times 10 \text { reps @ } \\
\text { moderate resistance }\end{array}$ & $\begin{array}{l}2 \text { Sets } \times 10 \text { reps @ } \\
\text { moderate resistance }\end{array}$ \\
\hline Hip flexion & $\begin{array}{l}1 \text { Set } \times 10 \text { reps } @ \\
\text { low resistance }\end{array}$ & $\begin{array}{l}2 \text { Sets } \times 10 \text { reps } @ \\
\text { low resistance }\end{array}$ & $\begin{array}{l}1 \text { Set } \times 10 \text { reps @ } \\
\text { moderate resistance }\end{array}$ & $\begin{array}{l}2 \text { Sets } \times 10 \text { reps @ } \\
\text { moderate resistance }\end{array}$ \\
\hline ension & $\begin{array}{l}1 \text { Set } \times 10 \text { reps @ } \\
\text { low resistance }\end{array}$ & $\begin{array}{l}2 \text { Sets } \times 10 \text { reps @ } \\
\text { low resistance }\end{array}$ & $\begin{array}{l}1 \text { Set } \times 10 \text { reps @ } \\
\text { moderate resistance }\end{array}$ & $\begin{array}{l}2 \text { Sets } \times 10 \text { reps @ } \\
\text { moderate resistance }\end{array}$ \\
\hline $\begin{array}{l}\text { Foot plantar } \\
\text { flexion }\end{array}$ & $\begin{array}{l}1 \text { Set } \times 10 \text { reps @ } \\
\text { low resistance }\end{array}$ & $\begin{array}{l}2 \text { Sets } \times 10 \text { reps } @ \\
\text { low resistance }\end{array}$ & $\begin{array}{l}1 \text { Set } \times 10 \text { reps @ } \\
\text { moderate resistance }\end{array}$ & $\begin{array}{l}2 \text { Sets } \times 10 \text { reps @ } \\
\text { moderate resistance }\end{array}$ \\
\hline Foot dorsiflexion & $\begin{array}{l}1 \text { Set } \times 10 \text { reps } @ \\
\text { low resistance }\end{array}$ & $\begin{array}{l}2 \text { Sets } \times 10 \text { reps @ } \\
\text { low resistance }\end{array}$ & $\begin{array}{l}1 \text { Set } \times 10 \text { reps } @ \\
\text { moderate resistance }\end{array}$ & $\begin{array}{l}2 \text { Sets } \times 10 \text { reps @ } \\
\text { moderate resistance }\end{array}$ \\
\hline $\begin{array}{l}\text { Step ups-forward/ } \\
\text { lateral both } \\
\text { sides }\end{array}$ & $\begin{array}{l}8 \text { Steps each } \\
\text { direction with } \\
3^{\prime \prime} \text { step height }\end{array}$ & $\begin{array}{l}12 \text { Steps each } \\
\text { direction with } 53 " \\
\text { step height }\end{array}$ & $\begin{array}{l}16 \text { Steps each } \\
\text { direction with } \\
5^{\prime \prime} \text { step height }\end{array}$ & $\begin{array}{l}20 \text { Steps each } \\
\text { direction with } \\
73^{\prime \prime} \text { step height }\end{array}$ \\
\hline Cool down & $\begin{array}{l}\text { Static stretching } \\
\text { (all muscle } \\
\text { groups) and } \\
5 \text { min of walking }\end{array}$ & $\begin{array}{l}\text { Static stretching } \\
\text { (all muscle } \\
\text { groups) and } \\
5 \text { min of walking }\end{array}$ & $\begin{array}{l}\text { Static stretching (all } \\
\text { muscle groups) and } \\
5 \text { min of walking }\end{array}$ & $\begin{array}{l}\text { Static stretching (all } \\
\text { muscle groups) and } \\
5 \text { min of walking }\end{array}$ \\
\hline
\end{tabular}

Table 2. Selected baseline characteristics for UC + EX and UC groups. ${ }^{*} \dagger$

\begin{tabular}{|c|c|c|c|c|}
\hline Variable & Exercise $(n=36)$ & Control $(n=35)$ & Test statistic & $p$ Value \\
\hline Age $(y)$ & $\begin{array}{l}63.1(7.3) \\
60.7-65.5\end{array}$ & $\begin{array}{l}62.6(7.6) \\
60.1-65.1\end{array}$ & $t=0.31$ & 0.76 \\
\hline Weight (kg) & $\begin{array}{l}98.9(19.9) \\
92.4-105.4\end{array}$ & $\begin{array}{l}95.3(23.4) \\
87.6-103.1\end{array}$ & $t=0.71$ & 0.48 \\
\hline $\mathrm{BMl}\left(\mathrm{kg} \cdot \mathrm{m}^{2}\right)$ & $\begin{array}{l}35.9(8.5) \\
33.1-38.7\end{array}$ & $\begin{array}{l}32.9(5.7) \\
31.0-34.8\end{array}$ & $t=1.74$ & 0.09 \\
\hline No. of repetitions & $\begin{array}{l}2,271.1(2,757.6) \\
1,370.3-3,171.9\end{array}$ & Not applicable & & \\
\hline $\begin{array}{l}\text { No. of prehabilitation } \\
\text { sessions }\end{array}$ & $\begin{array}{l}13.4(8.0) \\
10.8-16.0\end{array}$ & Not applicable & & \\
\hline $\begin{array}{l}\text { No. of repetitions per } \\
\text { session }\end{array}$ & $\begin{array}{l}175(344.6) \\
62.4-287.6\end{array}$ & Not applicable & & \\
\hline Race & $\begin{array}{l}\text { White }=28 \\
\text { Minority }=7 \\
\text { No response }=1\end{array}$ & $\begin{array}{l}\text { White }=30 \\
\text { Minority }=4 \\
\text { No response }=1\end{array}$ & $x^{2}=1.83$ & 0.40 \\
\hline Gender & $\begin{array}{l}\text { Men }=12 \\
\text { Women }=24\end{array}$ & $\begin{array}{l}\text { Men }=13 \\
\text { Women }=22\end{array}$ & $x^{2}=0.11$ & 0.73 \\
\hline
\end{tabular}


used to assess the subject's perception of pain (18) after completing each task discussed below.

The first functional task assessed was the distance covered in a 6-minute walk. Previous investigators have assessed the functional ability of individuals' scheduled for TKA pre and postoperatively using this protocol with minimal reports of injury $(14,17)$. Each subject was instructed to cover as much distance as possible within 6 minutes while walking around an indoor 36-m oval course, which was marked off in 1-m increments. Subjects were instructed that they could stop at any point during the test if they experienced fatigue or pain and could resume walking once they felt capable of continuing. At the end of the 6 minutes, the total distance walked in meters (tenth of a meter) was recorded.

Subjects then completed a 30-second sit -to-stand test. Each subject began this assessment seated on a padded 68-cm-high bench, which had no arms or back. Each subject assumed an upright standing position followed by a seated position as many times as possible within a 30 -second time interval. The number of complete stands (up from and then down to the bench) was recorded. This assessment has demonstrated high validity (19) by being correlated with a 1 repetition maximum ( $1 \mathrm{RM}$ ) leg press ( $r=0.78 \mathrm{men} / \mathrm{O} .71$ women) and strong test-retest reliability ( $r=0.89)$. In addition a VAS (1-10) was used to assess the subject's perception of pain after completing each task (18).

The third test of till1ction required the subjects to ascend 2 continuous flights of 11 stairs and then descend these same stairs after a 30-second rest period (step height $=18$ $\mathrm{cm})$. The test began with the subject standing facing the stairs with their hands at their sides. Subjects were instructed that the handrails could be used as needed to assist with balance while ascending or descending the stairs. The times to complete both the first and second flight of stairs were recorded (tenth of a second). Completion of a flight was determined when both feet arrived on the final stair. Previous studies reported a high degree of sensitivity of this assessment to exercise training among individuals with knee OA and functionally limited older adults $(32,33)$. In addition a VAS (1-10) was used to assess the subject's perception of pain after completing each task.

Isokinetic strength of the quadriceps (knee extension) and hamstrings (knee flexion) were measured bilaterally using a Biodex System 3 Version 3.30 dynamometer (Biodex Medical Systems, Inc., Shirley, NY, USA). The protocol used was similar to that developed by Topp and Mikesky $(31,32)$, which was adapted from Elsner et al. (9). Knee movement was isolated through the use of Velcro straps on the trunk, waist, and thigh. Strength was Swank et al., 5 
assessed through 3 repetitions of knee extension and flexion at maximal exertion with each trial separated by a 10 -second rest period. The dynamometer was set to resist each motion at $60^{\circ} \cdot \mathrm{s}^{-1}$. Subjects were informed of the purpose of the test and given an opportunity to become familiar with the testing equipment. Reliability of an isokinetic dynamometer using a similar protocol (31) has been found acceptable for determining strength among older adults $(r=0.91-0.94)$. The peak torque to body weight $(\mathrm{kg})$ of all 3 trials was recorded for both flexion and extension with the highest measure for each motion used for statistical analysis.

After $\mathrm{T} 1$ testing, subjects were randomized into UC or UC + EX. Subjects assigned to UC were asked to continue their normal activities until their TKA. Subjects assigned to $U C+E X$ were asked to exercise a minimum of 3 sessions per week. One of these 3 weekly sessions was conducted under the supervision of the research personnel, whereas the other weekly sessions were conducted by the subject in their home. Immediately after randomization, subjects in UC + EX were taught each exercise and were instructed how to conduct each exercise session. The exercise program emphasized 3 components: resistance training, flexibility, and step training. Subjects documented their compliance with the treatment using an exercise log (average compliance with exercise program was $90 \%$ of expected exercise sessions).

Table 1 shows the progression of the exercise dosage during the weeks before surgery. A single exercise session started with a 5-minute warm-up consisting of walking. The warm-up was followed by 9 lower body resistance training exercises including squats, hip flexion, and extension, hip abduction and adduction, ankle plantar flexion and dorsiflexion, knee extension and flexion; each conducted with Thera-Band bands (Hygienic Corporation, Akron, $\mathrm{OH}, \mathrm{USA}$ ). The intensity of the resistance was designed to be moderately fatiguing. After completing the resistance exercises, subjects performed a series of forward and lateral step training. Each exercise session was concluded with a cool-down of light static stretching that included gluteal, hip, hamstring, calf, torso, upper back, lower back, and tricep stretches followed by 5 minutes of walking.

\section{Statistical Analyses}

Data analysis was completed in 3 steps: data input and verification, descriptive analysis, and statistical analysis to address the hypothesis. The data for all outcome variables were entered twice into separate Excel spreadsheets and compared with any discrepancies checked against the original data collection form. Once verified, data were Swank et al., 6 
transferred to an SPSS 15.0 (SPSS Inc., Chicago, IL, USA) data file for descriptive and inferential analyses. Descriptive analysis was conducted to determine if the data violated the assumptions of parametric testing and to describe the sample to determine the extent of the external validity of the findings. An independent $t$-test for descriptive variables was used to determine presence of significant differences for descriptive variables. Repeatedmeasures analysis of variance (R-ANOVA) was calculated using univariate analysis to determine group by time interaction changes for each of the strength, function and pain outcome variables. A $t$-test post hoc for performance variables was used to determine the presence of significant differences between groups. The outcome variables included measures of performance of functional tasks and extension and flexion peak torque strength of the surgical and nonsurgical leg. A small number of UC + EX $(n=3)$ and UC subjects $(n=3)$ reported that they could not complete either the ascending or descending stair assessment and were excluded from the analysis of these outcome variables. An alpha level of 0.05 was set a priori to determine significance.

\section{Results}

Table 2 presents relevant subject characteristics (means, SD and $95 \%$ confidence interval). The entire sample was approximately 63 years old, overweight as evidenced by an average body mass index (BMI) in excess of $32 \mathrm{~kg} \mathrm{~m}^{2}$ and predominately older white women. The UC + EX group exercised an average of 13.4 total sessions with 175 repetitions per session. Variability for both of these factors was high, likely a function of the 4- to 8-week training program. Analyses indicate the 2 study groups were similar in age, weight, BMI, race and gender distributions indicating the effectiveness of randomization.

Table 3 presents the means, SDs, percent change, and 95\% confidence intervals of the outcome variables between the 2 study groups at T1 and T2. The 2 groups were not significantly different $(p>0.05)$ in any of the outcome variables at T1. A significant group by time interaction was found for the number of sit-to-stand repetitions in 30 seconds ( $p=0.03)$, time to ascend the first $(p=0.02)$ and second $(p=0.05)$ flight of stairs, and peak extension torque in the surgical leg $(p=0.01)$. These findings support the hypothesis that older adults with severe knee $O A$ who engage in a resistance band and step exercise program before their TKA improve their knee flexion and extension strength and the ability to perform some of the functional tasks. 
Table 3. Outcomes between UC + EX and UC groups at T1 and T2 * $†$

\begin{tabular}{|c|c|c|c|c|c|c|}
\hline Outcomes & $\begin{array}{l}\text { Exercise } \\
\text { baseline } \\
(n=37)\end{array}$ & $\begin{array}{l}\text { Control } \\
\text { baseline } \\
(n=36)\end{array}$ & $\begin{array}{c}p \text { Value } \\
\text { for } \\
\text { baseline }\end{array}$ & $\begin{array}{c}\text { Exercise } \\
\text { presurgery } \\
(n=37)\end{array}$ & $\begin{array}{c}\text { Control } \\
\text { presurgery } \\
(n=36)\end{array}$ & $\begin{array}{l}\rho \text { Value for } \\
\text { group/time } \\
\text { interaction }\end{array}$ \\
\hline 6-min walk distance $(\mathrm{m})$ & $\begin{array}{l}387.6(16.5) \\
382.3-392.9\end{array}$ & $\begin{array}{l}374.8(16.5) \\
369.4-380.2\end{array}$ & 0.52 & $\begin{array}{c}392.8(15.2) \\
1.3 \% \\
387.9-397.7\end{array}$ & $\begin{array}{c}363.3(15.6) \\
-3.0 \% \\
358.2-368.4\end{array}$ & 0.14 \\
\hline Sit-to-stand repetitions (no.) & $\begin{array}{l}10.3(0.60) \\
10.1-10.5\end{array}$ & $\begin{array}{l}9.7(0.62) \\
9.5-9.9\end{array}$ & 0.51 & $\begin{array}{r}11.5(0.65) \\
11.7 \% \\
11.3-11.7\end{array}$ & $\begin{array}{c}9.6(0.68) \\
-1.0 \% \\
9.4-9.8\end{array}$ & 0.03 \\
\hline $\begin{array}{l}\text { Ascend time-first flight of } \\
\text { stairs (s) }\end{array}$ & $\begin{array}{l}11.8(1.4) \\
(n=35) \\
11.3-12.3\end{array}$ & $\begin{array}{l}10.3(1.4) \\
\langle n=36) \\
9.8-10.8\end{array}$ & 0.64 & $\begin{array}{c}11.0(1.3) \\
-6.8 \% \\
(n=35) \\
10.6-11.4\end{array}$ & $\begin{array}{c}11.1(1.3) \\
7.7 \% \\
(n=36) \\
10.7-11.5\end{array}$ & 0.02 \\
\hline $\begin{array}{l}\text { Ascend time-second flight of } \\
\text { stairs (s)\# }\end{array}$ & $\begin{array}{l}11.0(1.0) \\
(n=33) \\
10.7-11.3\end{array}$ & $\begin{array}{l}10.8(1.0) \\
(n=33) \\
10.5-11.1\end{array}$ & 0.92 & $\begin{array}{l}11.1(1.2) \\
0.9 \%(n=33) \\
10.7-11.5\end{array}$ & $\begin{array}{l}12.5(1.2) \\
15.7 \%(n=33) \\
12.1-12.9\end{array}$ & 0.05 \\
\hline $\begin{array}{l}\text { Descend time-first flight of } \\
\text { stairs (s) }\end{array}$ & $\begin{array}{l}13.0(1.8) \\
12.4-13.6\end{array}$ & $\begin{array}{l}10.8(2.0) \\
10.2-11.5\end{array}$ & 0.50 & $\begin{array}{r}12.0(1.9) \\
7.6 \% \\
11.4-12.6\end{array}$ & $\begin{array}{c}10.9(2.0) \\
-1.0 \% \\
10.3-11.6\end{array}$ & 0.21 \\
\hline $\begin{array}{l}\text { Descend time-second flight of } \\
\text { stairs (s) }\end{array}$ & $\begin{array}{l}11.4(1.3) \\
11.0-11.8\end{array}$ & $\begin{array}{l}12.1(1.3) \\
11.7-12.5\end{array}$ & 0.76 & $\begin{array}{r}11.0(1.3) \\
3.5 \% \\
10.6-11.4\end{array}$ & $\begin{array}{c}12.2(1.3) \\
-1.0 \% \\
11.8-12.6\end{array}$ & 0.43 \\
\hline $\begin{array}{l}\text { Peak torque extension with } \\
\text { surgical leg (PT/BW; } N \cdot m \text { ) }\end{array}$ & $\begin{array}{l}54.4(5.6) \\
52.7-56.2\end{array}$ & $\begin{array}{l}56.8(5.8) \\
54.9-58.7\end{array}$ & 0.92 & $\begin{array}{r}60.0(5.4) \\
10.3 \% \\
58.3-61.7\end{array}$ & $\begin{array}{l}50.7(5.5) \\
-10.7 \% \\
48.9-52.5\end{array}$ & 0.01 \\
\hline $\begin{array}{l}\text { Peak torque extension with } \\
\text { nonsurgical leg (PT/BW; } N \cdot m)\end{array}$ & $\begin{array}{l}76.0(7.4) \\
73.6-78.4\end{array}$ & $\begin{array}{l}76.7(7.6) \\
74.2-79.2\end{array}$ & 0.79 & $\begin{array}{r}78.9(7.2) \\
3.8 \% \\
76.6-81.2\end{array}$ & $\begin{array}{r}78.4(7.4) \\
2.2 \% \\
76.0-80.8\end{array}$ & 0.82 \\
\hline $\begin{array}{l}\text { Peak torque flexion with surgical } \\
\text { leg (PT/BW; } N \text {-m) }\end{array}$ & $\begin{array}{l}29.4(3.8) \\
28.2-30.6\end{array}$ & $\begin{array}{l}29.6(3.9) \\
28.3-30.9\end{array}$ & 0.74 & $\begin{array}{r}32.3(3.7) \\
9.8 \% \\
31.1-33.5\end{array}$ & $\begin{array}{c}27.1(3.8) \\
-8.1 \% \\
25.9-28.3\end{array}$ & 0.12 \\
\hline $\begin{array}{l}\text { Peak torque flexion with } \\
\text { nonsurgical leg (PT/BW; } N \cdot m)\end{array}$ & $\begin{array}{l}38.7(4.0) \\
37.4-40.0\end{array}$ & $\begin{array}{l}36.8(4.1) \\
35.5-38.1\end{array}$ & 0.71 & $\begin{array}{r}39.8(4.2) \\
2.8 \% \\
38.5-41.2\end{array}$ & $\begin{array}{r}36.0(4.2) \\
-2.2 \\
34.6-37.4\end{array}$ & 0.50 \\
\hline
\end{tabular}

Table 4. Pain levels during performance of functional tasks using VAS. ${ }^{*} \dagger$

\begin{tabular}{|c|c|c|c|c|c|}
\hline Outcome & $\begin{array}{l}\text { Exercise } \\
\text { baseline } \\
(n=36)\end{array}$ & $\begin{array}{l}\text { Control } \\
\text { baseline } \\
(n=35)\end{array}$ & $\begin{array}{c}\text { Exercise } \\
\text { Presurgery } \\
(n=36)\end{array}$ & $\begin{array}{c}\text { Control } \\
\text { presurgery } \\
(n=35)\end{array}$ & $\begin{array}{c}\rho \text { Value for } \\
\text { group } \times \text { time } \\
\text { interaction }\end{array}$ \\
\hline 6-min walk & $\begin{array}{l}5.2(0.39) \\
5.1-5.3\end{array}$ & $\begin{array}{l}4.3(0.38) \\
4.2-4.4\end{array}$ & $\begin{array}{l}4.3(0.38) \\
17.3 \% \\
4.2-4.4\end{array}$ & $\begin{array}{l}5.1(0.42) \\
-18.6 \% \\
5.0-5.2\end{array}$ & 0.33 \\
\hline Sit to stand & $\begin{array}{l}4.5(0.41) \\
4.4-4.6\end{array}$ & $\begin{array}{l}4.0(0.40) \\
3.9-4.1\end{array}$ & $\begin{array}{c}5.3(0.44) \\
-17.7 \% \\
5.2-5.4\end{array}$ & $\begin{array}{l}4.7(0.43) \\
-17.5 \% \\
4.6-4.8\end{array}$ & 0.89 \\
\hline Stair ascend & $\begin{array}{l}5.0(0.44) \\
4.9-5.1\end{array}$ & $\begin{array}{l}3.8(0.43) \\
3.7-3.9\end{array}$ & $\begin{array}{l}5.9(0.45) \\
-18.0 \% \\
5.8-6.1\end{array}$ & $\begin{array}{l}4.6(0.44) \\
-21.1 \% \\
4.5-4.8\end{array}$ & 0.87 \\
\hline Stair descend & $\begin{array}{l}5.5(0.41) \\
5.4-5.6\end{array}$ & $\begin{array}{l}4.5(0.40) \\
4.4-4.6\end{array}$ & $\begin{array}{l}6.1(0.44) \\
-10.9 \% \\
6.0-6.2\end{array}$ & $\begin{array}{l}4.8(0.44) \\
-6.6 \% \\
4.7-5.0\end{array}$ & 0.69 \\
\hline
\end{tabular}

*VAS = visual analog scale; $\mathrm{T} 1$ = baseline; $\mathrm{T} 2$ = presurgery

†Values are given as mean (SD) and \% change baseline (T1) and to presurgery (T2).

Swank et al., 8 
Table 4 presents means, $S D$ s, and percent change of the pain levels between the $U C$ and UC + EX groups measured using a 0-10 VAS. These scores were obtained immediately after completion of the 4 functional tasks (26). No significant differences $(p>0.05)$ were found for pain scores between the 2 experimental groups.

Figure 1. Theory of prehabilitation $(8,33)$.

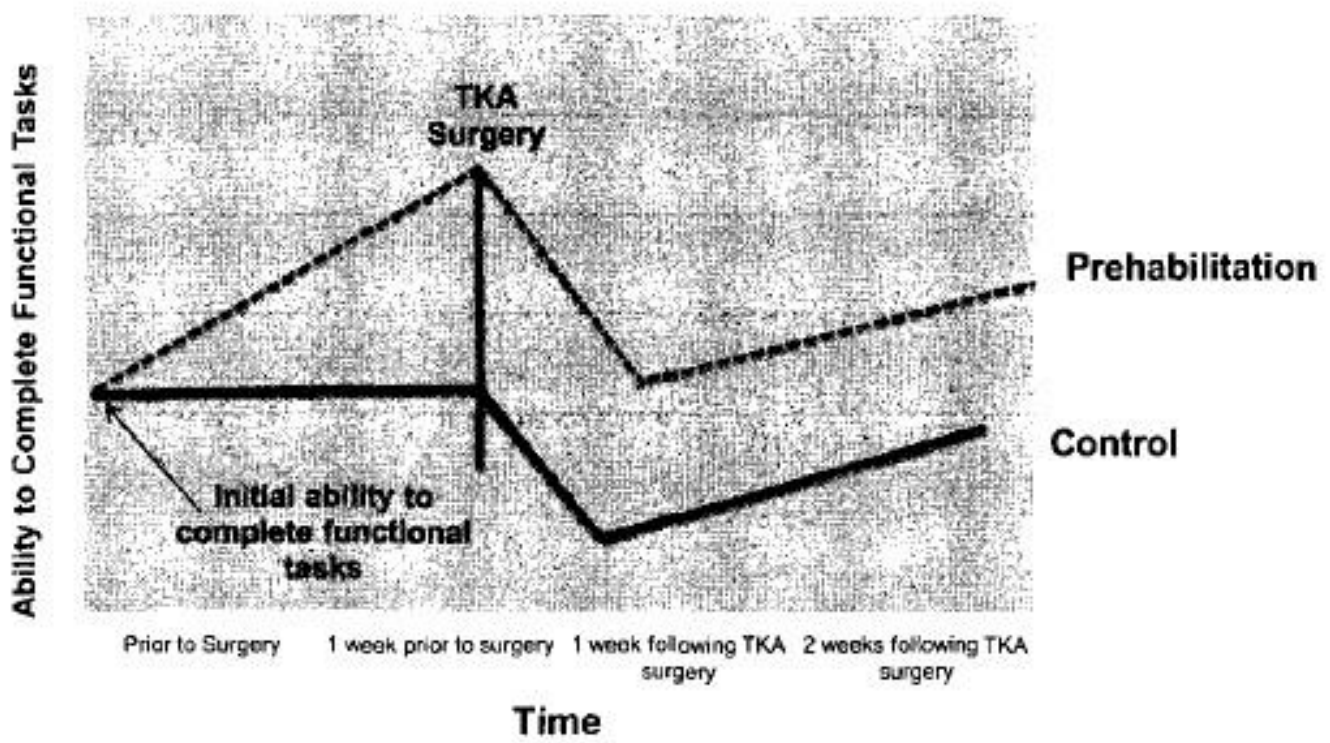

\section{Discussion}

This study demonstrated that exercise before TKA (prehabilitation) improved leg strength and the ability to perform functional tasks for older adults with severe $O A$ and pain intractable to medication. Increases in leg strength and performance of functional tasks before TKA surgery may result in improved postoperative recovery because pre0operative performance of functional tasks has been shown to be a predictor of postoperative performance of functional tasks $(13,23,25)$. Other studies evaluating the impact of exercise before surgery were not able to demonstrate an impact on function, likely related to measuring only the perception and self-report of functional ability rather than through direct assessment. Beaupre et al. (2) reported that 4 weeks of exercise and education before surgery had no effect on perceived functional ability or leg strength before or after TKA surgery. Similarly, D'Lima et al. (8) reported that 6 weeks of either resistance or cardiovascular training before TKA had no effect on self-reported measures of functional abilities before or after surgery. More recently, Rooks et al. (27), reported that 6 weeks of

Swank et al., 9 
aerobic and resistance training had no effect on perceived functional ability despite an increase in leg strength of $20 \%$ among the subjects with knee OA before undergoing TKA.

A number of investigators have observed that individuals with knee OA present with significantly lower quadriceps strength compared to their nonaffected leg or with healthy age-matched controls $(21,24)$. Mizner et al. $(23)$ reported that this reduction in strength is because the inability to fully activate the quadriceps muscle group and this reduced strength appears to continue after the TKA. These same authors later reported preoperative quadriceps strength to be a significant positive predictor of the ability to perform functional tasks, including stair climbing and rising from a chair, up to 1 year after TKA (22-25). Their findings were consistent with other researchers who reported that preoperative functional ability was a significant predictor of postoperative functional ability among individuals after TKA (13). These studies indicate that the declines in leg strength and ability to perform functional tasks associated with knee OA are not resolved after the TKA.

The prehabilitation exercise program assessed in this investigation had the greatest impact on the surgical leg with little if any measurable impact on the nonsurgical leg. The extension and flexion strength of the surgical leg at T1 was weaker than the nonsurgical leg. This finding of asymmetry in strength between the surgical and nonsurgical leg was reduced at T2 in the UC + EX group, but persisted in the UC group. The increase in strength in the surgical leg but no the nonsurgical leg may be attributed in part, to a relatively higher intensity exercise dosage in the surgical vs. the nonsurgical leg because of the asymmetry of starting strength. A number of other investigators have observed asymmetry of leg strength between the surgical and nonsurgical legs before TKA and have reported this asymmetry can continue for up to 12 months after the individual's TKA $(10,29)$. Rossi et al. (28) reported that 8 weeks of exercise after TKA did not resolve the asymmetry in strength between the surgical and nonsurgical legs. Thus, weakness in the surgical leg is not resolved after TKA surgery even with the addition of focused exercise after the TKA. The results of this study indicate that this leg strength asymmetry may be reduced through the introduction of prehabilitation exercises before the TKA. Reduced leg strength asymmetry may also have contributed to improved performance of functional tasks among the subjects who participate in the prehabilitation exercises.

Both the 6-minute walk and stair descent times were not impacted by the exercise protocol. The lack of change in the stair descent test for the UC + EX group may be attributed to the greater impact loads in the leg during descending stairs and the greater Swank et al., 10 
dependency on eccentric contraction of the quadriceps. This force generated in an $O A$ diseased knee joint may result in increases in joint pain during the activity resulting in the individual slowing their performance of this task. The exercise program involved resistance, flexibility, and step training, which were designed to improve performance of the functional tasks assessed. These prehabilitation exercises did not include walking or aerobic training, which may have contributed to the lack of impact of the exercise training on the performance of the 6-minute walk. Future studies may evaluate the impact of individualized prehabilitation exercises specific to the strength, aerobic capacity, or functional deficits within the individual.

The initial training volume was set at a low level for even the most detrained subjects to be able to complete the exercise protocol. This volume, although low, was sufficient to elicit a training response from the UC + EX group. Even though subjects were given verbal and written instructions on the progression of their exercise volume, the training logs kept by the subjects did not indicate a strict adherence to this progression. Thus, the principles of overload and progression may not have been adhered to in all UC + EX subjects. To increase compliance, future studies may consider increasing phone follow-ups for homebased programs to more than once a week or provide supervision for all prehabilitation sessions. In addition, it may be necessary to increase both education of the subject's with respect to importance of the exercise progression to maximize outcomes and increase the stair supervision for this short-term program.

The increased pain observed in the UC group may explain in part the declines in leg strength and ability to perform functional tasks observed among these subjects. It was the practice of the orthopedic surgeon to discontinue the individual's nonsteroidal antiinflammatory analgesics during the week before their TKA when the T2 testing took place. The results indicate a decline in strength and ability to perform functional tasks among the $\mathrm{UC}$ group between $\mathrm{TI}$ and $\mathrm{T} 2$. The UC + EX subjects increased leg strength and ability to perform functional tasks between $\mathrm{Tl}$ and $\mathrm{T} 2$. The gains in leg strength and performance of functional tasks between $\mathrm{Tl}$ and $\mathrm{T} 2$ observed in the UC + EX group were made when pain medications were discontinued which further validates the findings of increased strength and function as a result of prehabilitation.

The results of the current investigation using measures of leg strength and performance of functional tasks indicates that the implementation of a resistance band and step exercise program can increase leg strength in the surgical leg, decrease leg strength Swank et al., 11 
asymmetry, and increase the ability to perform functional tasks for individuals with severe OA before TKA. Previous researchers have shown leg strength deficits can be present for up to a year after TKA $(23,25)$. Results from this study indicate that leg strength and performance of functional tasks can be improved upon before TKA surgery, which has the potential to accelerate the rehabilitation process after TKA.

\section{Practical Applications}

The current investigation evaluated the impact of a comprehensive, easily accessible prehabilitation exercise program performed before TKA surgery for individuals with endstage $O A$ and pain intractable to medication. The prehabilitation exercise program consisted of 4 to 8 weeks of modest resistance training with Thera-Bands, flexibility, step exercise, and light walking performed 3 times per week both in the clinic and at home. The underlying theory of the potential impact of prehabilitation on postsurgery performance is outlined in Figure 1. If prehabilitation is successful, there is the potential, although speculative, that the individual will enter surgery after prehabilitation stronger than without prehabilitation and that this level of performance would not drop off as far as a result of surgery. The results of the current investigation indicate the efficacy of prehabilitation exercise and are helpful for clinicians working with the OA population as the implementation of a resistance band and step exercise program increased leg strength in the surgical leg, decreased leg strength asymmetry, and increased the ability to perform functional tasks for individuals with $O A$ before TKA. The positive changes found are significant as the program served individuals with end-stage OA for whom the only relief of pain was to have the TKA surgery.

\section{Acknowledgements}

Funding source: This study was funded by the National Institute of Nursing Research (R01NR008135) and the Hygenic Corporation, Akron Ohio.

\section{References}

1. American College of Sports Medicine. Guidelines for Exercise Testing and Prescription (6 $6^{\text {th }}$ ed.). Philadelphia, PA: Lippincott Williams \& Wilkins: 2000. Pp. 35-50.

2. Beaupre, LA, Lier, D, Davies, DM, and Johnston, DB. The effect of a preoperative exercise and education program on functional recovery, health related quality of life, and

Swank et al., 12 
health service utilization following primary total knee arthroplasty. $J$ Rheumato/ 31 : 1166-1173, 2004.

3. Brady, OH, Masri, BA, Garbuz, DS, and Duncan, CP. Joint replacement of the hip and knee - when to refer and what to expect. CMAJ 163: 1285-1291, 2000.

4. Centers for Disease Control and Prevention. Arthritis prevalence and activity limitations - United States, 1990. MMWR-Morb Mortal Wkly Rep 43: 433-438, 1994.

5. Centers for Disease Control and Prevention. Prevalence of disabilities and associated health conditions among adults - United States, 1999. [erratum appears in MMWR Morb Mortal Wkly Rep 50: 149, 2001]. MMWR-Morb Mortal Wkly Rep 50: 120-125, 2001.

6. Creamer, P. Current perspectives on the clinical presentation of joint pain in human OA. Novartis Found Symp 260: 64-74, 2004.

7. Ditmyer, MM, Topp, R, Pifer, M, Ditmyer, MM, Topp, R, and Pifer, M. Prehabilitation in preparation for orthopaedic surgery. Orthop Nurs 21: 43-51, 2002.

8. D'Lima, DD, Colwell, CW Jr, Morris, BA, Hardwick, ME, and Kozin, F. The effect of preoperative exercise on total knee replacement outcomes. Clin Orthop Relat Res. 326: 174-182, 1996.

9. Elsner, RC, Pedegana, LR, and Lang, J. Protocol for strength testing and rehabilitation of the upper extremity. JOSPT 4: 229-235, 1983.

10. Felicetti, G, Maini, M, Bazzini, G, Marchioni, M, and Giustini, A. [Assessment of function recovery in individuals with total knee prosthesis]. Giornale Italiano di Medicina del Lavoro Ed Ergonomia 26: 156-161, 2004.

11. Felson, DT, Lawrence, RC, Dieppe, PA, Hirsch, R, Helmick, CG, Jordan, JM, Kington, RS, Lane, NE, Nevitt, MC, Zhang, Y, Sowers, M, McAlindon, T, Spector, TD, Poole, AR, Yanovski, SZ, Ateshian, G, Sharma, L, Buckwalter, JA, Brandt, KD, and Fries, JF. Osteoarthritis: New insights. Part 1: The disease and its risk factors. Ann Intern Med 133: 635-646, 2000.

12. Felson, DT, Zhang, Y, Felson, DT, and Zhang, Y. An update on the epidemiology of knee and hip osteoarthritis with a view to prevention. Arth Rheum 41: 1343-1355, 1998.

13. Fortin, PR, Clarke, AE, Joseph, L, Liang, MH, Tanzer, M, Ferland, D, Phillips, C, Partridge, AJ, Bélisle, P, Fossel, AH, Mahomed, N, Sledge, CB, and Katz, JN. Outcomes of total hip and knee replacement: Preoperative functional status predicts outcomes at six months after surgery. Arthr Rheum 42: 1722-1728, 1999.

Swank et al., 13 
14. Fransen, M, Crosbie, J, Edmonds, J, Fransen, M, Crosbie, J, and Edmonds, J. Physical therapy is effective for individuals with osteoarthritis of the knee: A randomized controlled clinical trial. J Rheumatol 28: 156-164, 2001.

15. Hawker, GA, Guan, J, Croxford, R, Coyte, PC, Glazier, RH, Harvey, BJ, Wright, JG, Williams, JI, and Bradley, EM. A prospective population-based study of the predictors of undergoing total joint arthroplasty. Arthr Rheum 54: 3212-3220, 2006.

16. Hsu, RW, Tsai, YH, and Huang, TJ. Hybrid total knee arthroplasty: A 3- to 6-year outcome analysis. J Formosan Med Assoc 97: 410-415, 1998.

17. Hurwitz, DE, Ryals, AR, Block, JA, Sharma, L, Schnitzer, TJ, and Adriacchi, TP. Knee pain and joint loading in subjects with osteoarthritis of the knee. J Orthop Res 18: 572 579, 2000.

18. Jensen, MP, Karoly, P, and Braver, S. The measurement of clinical pain intensity: A comparison of six methods. Pain 27: 117-126, 1986.

19. Jones, CJ, Rikli, RE, Beam, WC, Jones, CJ, Rikli, RE, and Beam, WC. A 30-s chairstand test as a measure of lower body strength in community-residing older adults. Res Q Exerc Sport 70: 113-119, 1999.

20. Kamel, HK. Sarcopenia and aging. Nutr Rev 61: 157-167, 2003.

21. Lewek, MD, Rudolplh, KS, Snyder-Mackler, L, Lewek, MD, Rudolph, KS, and SnyderMackler, L. Quadriceps femoris muscle weakness and activation failure in individuals with symptomatic knee osteoarthritis. J Orthop Res 22: 110-115, 2004.

22. Mizner, RL, Petterson, SC, and Snyder-Mackler, L. Quadriceps strength and the time course of functional recovery after total knee arthroplasty. JOSPT 35: 424-436, 2005.

23. Mizner, RL, Petterson, SC, and Stevens, JE. Early quadriceps strength loss after total knee arthroplasty. The contributions of muscle atrophy and failure of voluntary muscle activation. J Bone Joint Surg 87: 1047-1053, 2005.

24. Mizner, RL, Petterson, SC, Stevens, JE, Axe, MJ, and Snyder-Mackler, L. Preoperative quadriceps strength predicts functional ability one year after total knee arthroplasty. $J$ Rheumatol 32: 1533-1539, 2005.

25. Mizner, RL and Snyder-Mackler, L. Altered loading during walking and sit-to-stand is affected by quadriceps weakness after total knee arthroplasty. J Orthop Res 23: 10831090, 2005.

26. Price, DD, McGrath, PA, Rafii, A, and Buckingham, B. The validation of visual analogue scales as ratio scale measures for chronic and experimental pain. Pain 17: 45-56, 1983.

Swank et al., 14 
27. Rooks, DS, Huang, J, and Bierbaum, BE. Effect of preoperative exercise on measures of functional status in men and women undergoing total hip and knee arthroplasty. Arthr Rheum 55: 700-708, 2006.

28. Rossi, MD, Brown, LE, Whitehurst, M, Rossi, MD, Brown, LE, and Whitehurst, M. Early strength response of the knee extensors during eight weeks of resistive training after unilateral total knee arthroplasty. J Strength Cond Res 19: 944-949, 2005.

29. Rossi, MD, Brown, LE, Whitehurst, M, Rossi, MD, Brown, LE, and Whitehurst, M. Knee extensor and flexor torque characteristics before and after unilateral total knee arthroplasty. Am J Phys Med Rehabil 85: 737-746, 2006.

30. Stevens, JE, Mizner, RL, and Snyder-Mackler, L. Quadriceps strength and volitional activation before and after total knee arthroplasty for osteoarthritis. J Orthop Res 21 : 775-779, 2003.

31. Topp, R, Boardley, D, and Morgan, AL. Exercise and functional tasks among adults who are functionally limited. West J Nurs Res. 27: 252-270, 2005.

32. Topp, $R$ and Mikesky, A. Reliability of isometric and isokinetic evaluations of ankle dorsi/plantar strength among older adults. Isokinet Exerc Sci 4: 157-163, 1994.

33. Topp, R, Woolley, S, and Hornyak, J. The effect of dynamic versus isometric resistance training on pain and functioning among adults with osteoarthritis of the knee. [see comment]. Arch Phys Med Rehab 83: 1187-1195, 2002. 